\title{
Corrigendum: The genetic landscape of benign thyroid nodules revealed by whole exome and transcriptome sequencing
}

Lei Ye, Xiaoyi Zhou, Fengjiao Huang, Weixi Wang, Yicheng Qi, Heng Xu, Yang Shu, Liyun Shen, Xiaochun Fei, Jing Xie, Min Cao, Yulin Zhou, Wei Zhu, Shu Wang, Guang Ning \& Weiqing Wang

Nature Communications 8:15533 doi: 10.1038/ncomms15533 (2017); Published 5 Jun 2017; Updated 4 Jul 2017

The original version of this Article contained an error in the formatting of the author name Yang Shu, which was incorrectly given as Shu Yang. This has now been corrected in both the PDF and HTML versions of the Article.

(c) Open Access This article is licensed under a Creative Commons Attribution 4.0 International License, which permits use, sharing, adaptation, distribution and reproduction in any medium or format, as long as you give appropriate credit to the original author(s) and the source, provide a link to the Creative Commons license, and indicate if changes were made. The images or other third party material in this article are included in the article's Creative Commons license, unless indicated otherwise in

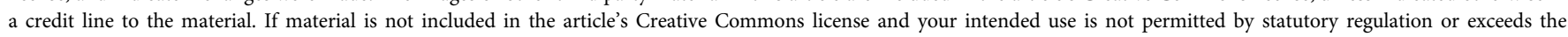
permitted use, you will need to obtain permission directly from the copyright holder. To view a copy of this license, visit http://creativecommons.org/licenses/by/4.0/

(C) The Author(s) 2017 